\title{
ANALISIS PENERAPAN BALANCED SCORECARD SEBAGAI ALAT PENGUKURAN KINERJA PERUSAHAAN (Studi Kasus pada PT Perkebunan Nusantara X Unit Pabrik Gula Lestari Kertosono)
}

\author{
Ika Yuniawati dan Juli Murwani \\ Prodi Pendidikan Akuntansi IKIP PGRI MADIUN \\ Email: Jmurwani@yahoo.com
}

\begin{abstract}
ABSTRAK
Penelitian ini bertujuan untuk mengetahui bagaimana kinerja Pabrik Gula Lestari Kertosono apabila diukur dengan menggunakan balanced scorecard. Dengan adanya balanced scorecard sebagai alat pengukur kinerja dapat membantu perusahaan mencapai tujuannya secara efektif dan efisien. Penelitian studi kasus ini dilakukan dengan menggunakan data tahun 2010-2012 pada PTPN X unit Pabrik Gula Lestari Kertosono untuk menganalisis prespektif keuangan, proses bisnis internal, dan stakeholder, sedangkan untuk prespektif pembelajaran dan pertumbuhan dilakukan analisis melalui kuisioner. Populasi dalam penelitian ini adalah karyawan Pabrik Gula Lestari. Sampel yang diambil adalah 100 responden untuk karyawan. Kuisioner tersebut telah diuji validitas dan reliabilitasnya. Indikator dalam penelitian ini terdiri dari ROI, TATO, FATO, Gross Profit Margin, akuisisi Stakeholder, retensi Stakeholder, profitabilitas stakeholder, pencapaian rendemen riil, pencapaian luas lahan tebu petani, pencapaian jumlah tebu giling, pencapaian produksi gula dan tetes, jam berhenti giling, retensi karyawan, produktivitas karyawan, dan kepuasan karyawan. Hasil analisis yang dilakukan, dapat diketahui bahwa kinerja Pabrik Gula Lestari secara keseluruhan adalah baik. Pada prespektif keuangan menunjukkan hasil yang cukup baik. Untuk prespektif stakeholder menunjukkan kinerja yang cukup baik. Pada prespektif bisnis internal menunjukkan bahwa tingkat rendemen melampaui target yang ditetapkan. Hasil yang positif juga ditunjukkan oleh prespektif pembelajaran dan pertumbuhan karena tingkat kepuasan karyawannya mencapai tingkat yang cukup memuaskan. Dari data penelitian tersebut dapat diambil kesimpulan bahwa dengan menggunakan balanced scorecard dapat memberikan gambaran yang lebih terstruktur dan menyeluruh.
\end{abstract}

Kata Kunci : Balanced Scorecard, Pengukuran Kinerja, Pabrik Gula

\section{PENDAHULUAN}

Menurut Erlinda dan Setio (2006) bahwa untuk meningkatkan kemampuan daya saing perusahaan, perusahaan menyadari bahwa dibutuhkan penerapan strategi yang tepat, kompetitif dan komprehensif serta sejalan dengan visi dan misi perusahaan. Zudia (2010: 1) menyebutkan bahwa selain tuntutan akan kemampuan bersaing, perusahaan juga dituntut untuk memiliki keunggulan yang dapat membedakan perusahaan yang satu dengan perusahaan lainnya. Disamping itu, dengan adanya pemanfaatan teknologi informasi sebagai sarana untuk menciptakan daya saing perusahaan membawa perubahan lingkungan bisnis yang semakin kompetitif. Edwin dan Se Tin (2011) menjelaskan, salah satu cara untuk mengikuti perkembangan industri dan menyiasatinya adalah dengan menerapkan sistem pengukuran kinerja yang diharapkan mampu memperbaiki kondisi perusahaan agar menjadi lebih baik serta mampu menghadapi kompetisi bisnis dengan perusahaan pesaing.

Perusahaan membutuhkan suatu sistem untuk mengukur kinerja perusahaan. Sistem tersebut disebut Balanced Scorecard. Sistem ini dapat digunakan perusahaan sebagai strategi meningkatkan kemampuan kinerja organisasi pada masa depan. Balanced Scorecard merupakan alat manajemen kontemporer yang didesain untuk meningkatkan kemampuan perusahaan dalam melipatgandakan kinerja keuangan luar biasa secara berkesinambungan 
(sustainable uotstanding financial performance) (Mulyadi, 2009: 3). Menurut Mathius dan Erna (2011) bahwa balance scorecard memiliki keistimewaan karena mengukur kinerja perusahaan baik dari sisi finansial maupun non finansial, yaitu prespektif keuangan, prespektif pelanggan, prespektif proses bisnis internal dan prespektif pembelajaran dan pertumbuhan.

PG Lestari merupakan BUMN yang bergerak dibidang manufaktur di wilayah Kertosono. Menurut Hanuma (2010:4) bahwa dengan menggunakan konsep Balanced scorecard diharapkan dapat membantu memberikan kerangka komprehensif untuk menterjemahkan visi ke dalam sasaran-sasaran strategik. Pengukuran kinerja dengan Balanced Scorecard tidak hanya menggunakan aspek keuangan saja, melainkan juga aspekaspek non keuangan guna mencapai keseimbangan pengukuran kinerja. Dengan balanced scorecard manajemen perusahaan dapat memonitor dan menyesuaikan implementasi dan strategi yang ditetapkan, dan apabila diperlukan membuat perubahan mendasar dalam strategi itu sendiri (Krismiaji Anni, 2011: 367).

Penulis berpendapat bahwa perusahaan tersebut perlu menerapkan sistem manajemen yang baik untuk mengendalikan dan memperbaiki sistem yang ada sehingga perusahaan dapat mencapai keseimbangan dari segala aspek yang diperlukan, serta mewujudkan visi dan misi perusahaan. Penggunaan balanced scorecard, dapat memberikan bahan untuk mengkomunikasikan visi, misi dan strategi, kemudian menginformasikan kepada seluruh pegawai tentang apa yang menjadi penentu sukses pada masa sekarang dan masa yang akan datang.

Berdasarkan kelebihan yang dimiliki oleh Balance Scorecard, maka penulis tertarik untuk mengukur kinerja perusahaan dengan menggunakan instrumen-instrumen yang terdapat dalam Balanced Scorecard kedalam Penelitian yang berjudul "Analisis Penerapan Balanced Scorecard Sebagai Alat Pengukuran Kinerja Perusahaan (Studi Kasus pada PT Perkebunan Nusantara X unit Pabrik Gula Lestari Kertosono)".

Batasan masalah yang ada dalam penelitian ini Tolak ukur yang digunakan peneliti hanya menggunakan empat prespektif dalam balanced scorecard, yaitu prespektif finansial, stakeholder, prespektif proses bisnis internal, serta pertumbuhan dan pembelajaran. Keempat prespektif tersebut dianggap mencukupi dengan sedikit perubahan nama dalam prespektif pelanggan menjadi prespektif stakeholder, hal ini sesuai dengan keunikan dari industri pabrik gula itu sendiri dimana di dalam pabrik gula tidak terdapat adanya pelanggan tetapi adanya stakeholder yang menjadi partner kerja pabrik gula tersebut. Berdasarkan uraian sebelumnya, dapat dirumuskan masalah yaitu "Bagaimana kinerja PG Lestari Kertosono jika diukur menggunakan Balanced Scorecard?"

\section{KAJIAN TEORI}

Balanced Scorecard merupakan suatu sistem manajemen, pengukuran, dan pengendalian yang secara cepat, tepat, dan komprehensif dapat memberikan pemahaman kepada manajer tentang performance bisnis (Yuwono et al, 2002: 8). Balanced scorecard merupakan mekanisme untuk menterjemahkan strategi-strategi dan taktik secara simultan sehingga kebijakan dan aktivitas dapat diukur mulai dari rencana, implementasi dan sampai kepada hasil (Sinaga, 2004). Menurut Mulyadi dalam Zudia Meirdania (2010: 21), menjelaskan bahwa balanced scorecard terdiri dari dua kata yaitu balanced dan scorecard. Scorecard artinya kartu skor, maksudnya adalah kartu skor yang digunakan untuk merencanakan skor yang diwujudkan di masa yang akan datang, sedangkan balanced artinya berimbang, maksudnya adalah untuk mengukur kinerja seseorang diukur secara berimbang dari dua prespektif yaitu finansial dan non finansial, jangka pendek dan jangka panjang, intern dan ekstern.

Dalam Balanced Scorecard terdapat empat prespektif penting yang digunakan untuk penilian kinerja. Empat aspek tersebut adalah: a) Prespektif Finansial; menurut Erlinda dan 
Setio (2006: 2), prespektif ini (finansial) bertujuan untuk menjawab pertanyaan, "untuk dapat berhasil secara finansial, bagaimana seharusnya perusahaan terlihat dimata para pemegang saham?". Dalam prespektif ini berbagai sasaran strategis dan indikator yang berhubungan dengan pencapaian kinerja keuangan diidentifikasikan dan ditetapkan, b) Prespektif Pelanggan; Menurut Rangkuti (2012: 76), dalam prespektif pelanggan Balanced Scorecard, manajemen harus dapat mengidentifikasi pelanggan dan segmen pasar dimana unit bisnis tersebut akan bersaing dan berbagai ukuran kinerja unit bisnis di dalam segmen sasaran, c) Prespektif Proses Bisnis Internal; Erlinda dan Setio (2006) menjelaskan bahwa prespektif ini bertujuan untuk menjawab pertanyaan, "Untuk dapat memberikan kepuasan kepada para pemegang saham dan pelanggan, bisnis proses apa yang harus dikuasai perusahaan?", d) Prespektif Pembelajaran dan Pertumbuhan; memberikan infrastuktur yang memungkinkan tujuan dalam ketiga prespektif lainnya dapat tercapai (Widodo, 2011). Sedang menurut Erlinda dan Setio (2006), prespektif ini bertujuan untuk menjawab pertanyaan, "untuk dapat mewujudkan visi, bagaimana perusahaan memelihara kemampuan untuk berubah dan berkembang?".

Untuk mengukur tingkat kepuasan karyawan dilakukan berdasarkan survei dengan menyebarkan kuisioner. Isi dari kuisioner tersebut terdiri dari beberapa variabel yang berhubungan dengan faktor kepuasan karyawan. Kuisioner yang digunakan peneliti dalam penelitan ini dikembangkan dari penelitian terdahulu yang dilakukan oleh Sri Wahyuni(2011), jenis angket yang digunakan adalah kuisioner dengan Rating-scale (skala bertingkat) merupakan skala dimana responden menjawab salah satu dari jawaban kuantitatif yang disediakan untuk mengukur persepsi responden terhadap fenomena lainnya, seperti skala untuk mengukur status sosial ekonomi, kelembagaan, pengetahuan, kemampuan, proses kegiatan dan lain-lain (Sugiyono, 2012: 98). Jumlah kuesioner dibagikan kepada 100 karyawan sedangkan total pertanyaan dalam kuesioner adalah sebanyak 12 pertanyaan.

\section{METODE PENELITIAN}

Penelitian ini merupakan penelitian studi kasus pada salah satu perusahaan manufaktur di wilayah Kertosono. Penelitian kasus adalah suatu penelitian yang dilakukan secara intensif terinci dan mendalam terhadap suatu organisasi, lembaga atau gejala tertentu (Arikunto, 2010: 185). Tempat penelitian dilaksanakan di PG Lestari Kertosono yang beralamatkan Jalan Patianrowo Kertosono, Patianrowo, Nganjuk. Pendekatan yang digunakan dalam penelitian ini adalah pendekatan kualitatif. Sumber data penelitian kualitatif adalah tampilan yang berupa kata-kata lisan atau tertulis yang dicermati oleh peneliti, dan benda-benda yang diamati sampai detailnya agar dapat ditangkap makna yang tersirat dalam dokumen atau bendanya. Jenis penelitian yang digunakan dalam penelitian ini adalah penelitian kasus. Penelitian kasus adalah suatu penelitian yang dilakukan secara intensif terinci dan mendalam terhadap suatu organisasi, lembaga atau gejala tertentu (Arikunto, 2010: 185). Studi kasus penerapan Balanced Scorecard yang dilakukan di PG Lestari digunakan sebagai alat pengukuran kinerja perusahaan tersebut.

Data yang digunakan dalam penelitian ini adalah sumber data primer dan sumber data sekunder. Sumber data primer yang digunakan dalam penelitian ini diperoleh dari hasil wawancara dengan pihak perusahaan, data perusahaan, dan hasil penyebaran kuisioner yang dilakukan peneliti. Sumber data sekunder merupakan sumber data yang diperoleh secara tidak langsung atau melalui perantara yang dicatat oleh pihak lain. Pengumpulan data dalam penelitian ini menggunakan metode sebagai berikut :

1. Kuesioner (kepuasan karyawan)

2. Metode Wawancara

Metode ini juga dilakukan di beberapa bagian seperti tanaman, pabrikasi, akuntansi dan keuangan, dan SDM dan umum. Dengan melakukan wawancara di empat bagian tersebut, 
peneliti mendapatkan informasi yang berkaitan dengan empat prespektif balanced scorecard.

3. Dokumentasi

Dalam penelitian ini dokumentasinya berupa laporan Laba Rugi per 31 Desember 2010 dan 2012, Neraca per 31 Desember 2010 dan 2012, bagan struktur organisasi perusahaan, potret penelitian, Rencana Kerja Anggaran Perusahaan tahun 2010-2012, dan daftar stakeholder dan karyawan pada 2010 dan 2012.

Dalam balanced scorecard terdapat empat prespektif yang digunakan untuk mengukur kinerja perusahaan, prespektif tersebut antara lain:

a. Mengukur kinerja prespektif finansial

Prespektif ini menggunakan pengukuran ROI, TATO,FATO, dan Gross Profit Margin.

b. Mengukur kinerja Stakeholder

Dalam prespektif stakeholder yang diukur adalah tingkat akuisisi stakeholder, tingkat retensi stakeholder, dan tingkat profitabilitas stakeholder.

c. Prespektif Proses Bisnis dan Internal

Dalam prespektif proses bisnis dan internal yang diukur adalah pencapaian Rendemen

Riil, pencapaian Luas Lahan Tebu Petani, pencapaian jumlah tebu giling, pencapaian produksi gula, produksi tetes, dan jam berhenti giling.

d. Prespektif Pertumbuhan dan Pembelajaran

Dalam prespektif ini dapat digunakan pengukuran tingkat: Tingkat Produktivitas Karyawan, Retensi Karyawan dan Kepuasan Karyawan.

\section{PEMBAHASAN}

Konsep balanced scorecard dalam mengukur kinerja Pabrik Gula Lestari yang menggunakan empat prespektif yaitu: prespektif keuangan, stakeholder, proses bisnis internal serta pertumbuhan dan pembelajaran, dari tiap-tiap prespektif balanced scorecard tersebut, terdapat beberapa strategi yang diperoleh dari observasi dan wawancara dengan beberapa bagian di Pabrik Gula Lestari. Empat prespektif balanced scorecard membentuk hubungan sebab-akibat. Hubungan sebab akibat itu terhubung secara vertikal dengan empat prespektif balanced scorecard. Balanced scorecard menjalin hubungan kausal antara kepuasan karyawan dan keahlian karyawan, kepuasan petani dan keahlian petani, keefektivan proses bisnis yang pada akhirnya berpengaruh terhadap kinerja keuangan. Setelah itu, Pabrik Gula Lestari perlu untuk menterjemahkan hubungan kausal tersebut ke dalam sasaran, ukuran, target serta inisiatif yang digunakan sesuai dengan strategi yang dimiliki.

\section{A. Prespektif Keuangan}

Adapun ukuran-ukuran yang digunakan untuk menghitung kinerja keuangan pada Pabrik Gula Lestari adalah sebagai berikut :

1. ROI

Tabel 1. Return on Investment (ROI) Pabrik Gula Lestari Kertosono tahun 2010-2012

\begin{tabular}{lllll}
\multicolumn{5}{c}{ Kertosono tahun 2010-2012 } \\
\hline Tahun & Net Profit & Total asset & ROI (\%) & Naik/Turun (\%) \\
& $(1)$ & $(2)$ & $(3)=(1):(2)$ & \\
\hline 2010 & 17.222 .309 .098 & 83.314 .283 .493 & $20,6 \%$ & - \\
2011 & 19.595 .192 .665 & 79.582 .049 .145 & $24,6 \%$ & Naik 4\% \\
2012 & 29.556 .211 .876 & 106.253 .317 .670 & $27,8 \%$ & Naik 3,2\% \\
\hline
\end{tabular}

Sumber: Data sekunder yang diolah 
2. TATO

Tabel 2. Total Asset Turn Over Pabrik Gula Lestari Kertosono tahun 2010-2012

\begin{tabular}{lllll}
\hline Tahun & Sales & Total asset & TATO $(\%)$ & Naik/Turun \\
& $(1)$ & $(2)$ & $(3)=(1):(2)$ & \\
\hline 2010 & 98.853 .9188 .644 & 83.314 .283 .493 & 1,1865 & - \\
2011 & 117.600 .383 .579 & 79.582 .049 .145 & 1,4777 & Naik 0,2912 \\
2012 & 119.839 .388 .632 & 106.253 .317 .670 & 1,1278 & Turun 0,3499 \\
\hline
\end{tabular}

Sumber: Data sekunder yang diolah

3. FATO

Tabel 3. Fixed Asset Turn Over Pabrik Gula Lestari Kertosono tahun 2010-2012 \begin{tabular}{llll}
\hline Tahun Sales & Fixed Asset-net & FATO (\%) & Naik/Turun
\end{tabular}

$(3)=(1):(2)$

\begin{tabular}{lllll}
\hline 2010 & 98.853 .9188 .644 & 107.920 .200 .596 & 0,9159 & - \\
2011 & 117.600 .383 .579 & 115.476 .391 .804 & 1,0183 & Naik 0,1024 \\
2012 & 119.839 .388 .632 & 138.395 .902 .554 & 0,8659 & Turun 0,1524 \\
\hline
\end{tabular}

Sumber: Data sekunder yang diolah

4. Gross Profit Margin

Tabel 4. Gross Profit Margin Pabrik Gula Lestari Kertosono tahun 2010-2012

Sumber: Data sekunder yang diolah

\begin{tabular}{|c|c|c|c|c|c|c|}
\hline Tahun & Sales & $\begin{array}{l}\text { Cost of good } \\
\text { sold }\end{array}$ & Selisih & Sales & $\begin{array}{l}\text { Gross Profit } \\
\text { margin } \\
(\%)\end{array}$ & $\begin{array}{l}\text { Naik } \\
\text { /Turun } \\
(\%)\end{array}$ \\
\hline & (1) & (2) & $(3)=(1)-(2)$ & (4) & $(5)=(3):(4)$ & \\
\hline 2010 & 98.853 .918 .644 & $\begin{array}{l}83.416 .489 .00 \\
5\end{array}$ & 15.437 .429 .639 & 98.853 .918 .644 & $15,6 \%$ & - \\
\hline 2011 & 117.600 .383 .579 & $\begin{array}{l}97.546 .543 .78 \\
3\end{array}$ & 20.053 .839 .796 & 117.600 .383 .579 & $17 \%$ & $\begin{array}{l}\text { Naik } \\
1,4 \%\end{array}$ \\
\hline 2012 & 119.839 .388 .632 & $\begin{array}{l}90.333 .820 .36 \\
5\end{array}$ & 29.505 .568 .267 & 119.839 .388 .632 & $24,6 \%$ & $\begin{array}{l}\text { Naik } \\
7,6 \%\end{array}$ \\
\hline
\end{tabular}




\section{B. Prespektif Stakeholder}

Tabel 5. Rekapitulasi hasil pengukuran Kinerja Prespektif Stakeholder Pabrik Gula Lestari Kertosono tahun 2010 - 2012

\begin{tabular}{|l|l|l|l|l|l|l|}
\hline Tahun & \multicolumn{6}{|l|}{ Ukuran } \\
\cline { 2 - 7 } & $\begin{array}{l}\text { Akuisisi } \\
\text { Stakeholder }\end{array}$ & $\begin{array}{l}\text { Naik } \\
\text { /turun }\end{array}$ & $\begin{array}{l}\text { Retensi } \\
\text { Stakeholder }\end{array}$ & $\begin{array}{l}\text { Naik } \\
\text { /turun }\end{array}$ & $\begin{array}{l}\text { Profitabilitas } \\
\text { Stakeholder }\end{array}$ & $\begin{array}{l}\text { Naik } \\
\text { /turun }\end{array}$ \\
\hline 2010 & $9,5 \%$ & - & $90,5 \%$ & - & $17,42 \%$ & - \\
\hline 2011 & $5,7 \%$ & $-3,8 \%$ & $94,2 \%$ & $+3,7 \%$ & $16,66 \%$ & $-0,76 \%$ \\
\hline 2012 & $2,1 \%$ & $-3,6 \%$ & $79 \%$ & $-15,2 \%$ & $24,66 \%$ & $+8 \%$ \\
\hline
\end{tabular}

Sumber: data diolah peneliti

\section{Prespektif Proses Bisnis Internal}

a. Pencapaian target produksi

Analisis kinerja proses bisnis internal pada Pabrik Gula Lestari dapat dilihat dari kelancaran pasokan tebu yang akan dijadikan bahan baku utama. Agar pasokan bahan baku tidak terlambat bagian tanaman telah membuat rencana tebang sebelum musim giling datang. Diharapkan dengan membuat rencana tebang tersebut dapat meminimalisir keterlambatan bahan baku tebu yang akan berakibat tercapainya target produksi yang di inginkan.

b. Kapasitas Giling Harian Terpenuhi

Penataan varietas tebu dan peningkatan luas lahan tebu itu sendiri. Dari data yang dihasilkan oleh peneliti, Pabrik Gula Lestari telah melakukan pembagian varietas tebu sesuai dengan kematangan dan peningkatan luas lahan tebunya meningkat tiap tahunnya. Aktivitas seperti ini harus selalu dipertahankan dan ditingkatkan, karena dapat membantu memenuhi kebutuhan kapasitas giling dan target produksi.

c. Penurunan Jam Berhenti

Perusahaan memilihan tebu berkualitas tinggi. Pemilihan ini dilakukan dengan menerapkan Tebu Layak Tebang dan yang pasti memenuhi syarat rendemen minimal $8 \%$. Tebu yang masuk ke dalam pabrik akan segera digiling sesuai dengan kapasitas giling pabrik. Selama ini Pabrik Gula Lestari menerapkan proses seleksi tebu dengan efektif dan mengusahakan waktu tunggu tebu tidak lebih dari 48 jam setelah tebang, karena akan mempengaruhi kualitas gula yang dihasilkan.

d. Target Rendemen Terpenuhi

Bagian instalasi memastikan kesiapan mesin sebelum masa giling dimulai. Sebelum musim giling dimulai, dilakukan pengecekan mesin giling agar saat musim giling nanti tidak ada kerusakan mesin. Kerusakan mesin pada saat proses giling berjalan pastinya akan mempertinggi jam berhenti mesin sehingga target produksi akan terhambat dan kapasitas giling tidak terpenuhi. 
D. Prespektif Pembelajaran dan Pertumbuhan

Tabel 6. Rekapitulasi hasil pengukuran Kinerja Prespektif Pembelajaran dan Pertumbuhan Pabrik Gula Lestari Kertosono tahun 2010 - 2012

\begin{tabular}{lllll}
\hline Tahun & $\begin{array}{l}\text { Ukuran } \\
\text { Retensi } \\
\text { Karyawan }\end{array}$ & $\begin{array}{l}\text { Kepuasan } \\
\text { Karyawan }\end{array}$ & Produktivitas Karyawan & $\begin{array}{l}\text { Naik/ } \\
\text { Turun }\end{array}$ \\
\hline 2010 & $0 \%$ & & Rp. 19.093.469,06 & - \\
2011 & $0 \%$ & Rp 21.533.178,75 & + Rp 2.439.709,69 \\
2012 & $0 \%$ & Rp 32.694.924,64 & + Rp 11.161.745,89 \\
\hline
\end{tabular}

Sumber: data diolah peneliti

Tabel 7. Pengukuran Bobot Indikator dan Skor Tertimbang Maksimal

\begin{tabular}{|c|c|c|c|c|c|c|}
\hline Prespektif & Indikator Kerja & $\begin{array}{l}\text { Jumlah } \\
\text { Indikator }\end{array}$ & Bobot & $\begin{array}{c}\text { Bobot } \\
\text { Indikator }\end{array}$ & $\begin{array}{c}\text { Skor } \\
\text { Indikator }\end{array}$ & $\begin{array}{c}\text { Skor } \\
\text { Tertimbang } \\
\text { Maksimal }\end{array}$ \\
\hline Keuangan & $\begin{array}{l}\text { ROI } \\
\text { TATO } \\
\text { FATO } \\
\text { GPM }\end{array}$ & 4 & 26 & 6.5 & 4 & 104 \\
\hline Stakeholder & $\begin{array}{l}\text { Akuisisi } \\
\text { Retensi } \\
\text { Profitabilitas }\end{array}$ & 3 & 25 & 8,3 & 4 & 75 \\
\hline $\begin{array}{l}\text { Proses bisnis } \\
\text { internal }\end{array}$ & $\begin{array}{l}\text { Target produksi } \\
\text { Kapasitas giling } \\
\text { harian } \\
\text { Jam berhenti } \\
\text { giling } \\
\text { Target rendemen }\end{array}$ & 4 & 25 & 6,25 & 4 & 100 \\
\hline $\begin{array}{l}\text { Pembelajaran } \\
\& \\
\text { pertumbuhan }\end{array}$ & $\begin{array}{l}\text { Retensi } \\
\text { Produktivitas } \\
\text { Kepuasan }\end{array}$ & 3 & 24 & 8 & 4 & 72 \\
\hline & TOTAL & & 100 & & & 351 \\
\hline
\end{tabular}

\section{Sumber: Data Diolah Peneliti}

Keterangan:

Rumus skor tertimbang maksimum $=$ jumlah indikator $\mathrm{x}$ skor indikator maksimum $\mathrm{x}$ bobot indikator

Tahap selanjutnya adalah mengukur jumlah skor indikator keuangan dan memberikan nilai $\mathrm{A}=4, \mathrm{~B}=3, \mathrm{C}=2, \mathrm{D}=1$ dan untuk prespektif keuangan ditentukan sebagai berikut:

1. Nilai target $\mathrm{ROI}=30 \%$

Nilai minimum $=0$

Interval kelas ROI $=(30-0) / 4=7,5 \%$

Jadi kriteria skor indikator ROI adalah

$\mathrm{A}=22,5 \%-30 \%$

$\mathrm{B}=15 \%-<22,5 \%$

$\mathrm{C}=7,5 \%-<15 \%$

$\mathrm{D}=<7,5 \%$ 
2. Nilai target Total Asset Turn Over (TATO) $=25 \%$

Nilai minimum $=0$

Interval kelas TATO $=(25-0) / 4=6,25$

Jadi kriteria skor indikator TATO adalah

$\mathrm{A}=20-25$

$\mathrm{B}=15-<20$

$\mathrm{C}=10-<15$

$\mathrm{D}=<10$

3. Nilai target Fixed Asset Turn Over (FATO) $=25 \%$

Nilai minimum $=0$

Interval kelas FATO $=(25-0) / 4=6,25$

Jadi kriteria skor indikator TATO adalah

$\mathrm{A}=20-25$

$\mathrm{B}=15-<20$

$\mathrm{C}=10-<15$

$\mathrm{D}=<10$

4. Nilai target Gross Profit Margin $=20 \%$

Nilai minimum $=0$

Interval kelas Gross Profit Margin $=(20-0) / 4=5$

Jadi kriteria skor indikator Gross Profit Margin adalah

$\mathrm{A}=15 \%-20 \%$

$\mathrm{B}=10 \%-<15 \%$

$\mathrm{C}=5 \%-<10 \%$

$\mathrm{D}=<5 \%$

Nilai tersebut digunakan untuk menilai masing-masing indikator dalam prespektif keuangan yaitu Return on Investment (ROI), Total Asset Turn Over (TATO), Fixed Asset Turn Over (FATO), Gross Profit Margin. Sehingga nilai untuk masing-masing indikator dalam tiap prespektif adalah seperti tabel berikut: 
Tabel 8. Nilai Untuk Masing-Masing Indikator Dalam Prespektif Balanced Scorecard PG.

Lestari Kertosono Tahun 2010- 2012

\begin{tabular}{|c|c|c|c|c|c|c|}
\hline Prespektif & $\begin{array}{l}\text { Tahun } \\
2010\end{array}$ & 2011 & 2012 & Rata-rata & Nilai & $\begin{array}{l}\text { Skor } \\
\text { indikator }\end{array}$ \\
\hline \multicolumn{7}{|l|}{ Keuangan: } \\
\hline ROI & $20,6 \%$ & $24,6 \%$ & $27,8 \%$ & $24,3 \%$ & B & 3 \\
\hline TATO & 1,1865 & 1,4777 & 1,1278 & 1,264 & $\mathrm{C}$ & 2 \\
\hline FATO & 0,9159 & 1,0183 & 0,8659 & 0,9333 & $\mathrm{C}$ & 2 \\
\hline Gross Profit Margin & $\begin{array}{l}15,6 \% \\
\text { Total }\end{array}$ & $17 \%$ & $24,6 \%$ & $19,1 \%$ & B & $\begin{array}{l}3 \\
10\end{array}$ \\
\hline Stakeholder: & & & & & $\mathrm{C}$ & 2 \\
\hline Akuisisi stakeholder & $9,5 \%$ & $5,7 \%$ & $2,1 \%$ & $5,8 \%$ & $\mathrm{~B}$ & 3 \\
\hline Retensi stakeholder & $90,5 \%$ & $94,2 \%$ & $79 \%$ & $87,9 \%$ & $\mathrm{~B}$ & 3 \\
\hline Profitabilitas & $17,42 \%$ & $16,66 \%$ & $24,66 \%$ & $19,58 \%$ & & \\
\hline & \multicolumn{5}{|c|}{ Bisnis internal: } & 8 \\
\hline Target produksi & & & & & B & 3 \\
\hline \multicolumn{7}{|c|}{ ASSETS : Jurnal Akuntansi dan Pendidikan, Vol.3, No.1, April 2014} \\
\hline $\begin{array}{l}\text { Jam berhenti giling } \\
\text { Target rendemen }\end{array}$ & & & & & B & 3 \\
\hline & Total & & & & & 12 \\
\hline Learning & & & & & A & \\
\hline Growth: & & & & & $\mathrm{B}$ & 4 \\
\hline Retensi karyawan & $0 \%$ & $0 \%$ & $0 \%$ & $0 \%$ & B & 3 \\
\hline $\begin{array}{l}\text { Produktivitas } \\
\text { karyawan }\end{array}$ & Rp. 19.093.469,06 & Rp 21.533.178,75 & Rp 32.694.924,64 & $\begin{array}{l}\text { Rp 24.440.524,15 } \\
69,33 \%\end{array}$ & & 3 \\
\hline Kepuasan karyawan & Total & & & & & 10 \\
\hline
\end{tabular}

\section{Sumber: Data Diolah Peneliti}

Tahap selanjutnya adalah menghitung jumlah skor tertimbang dengan mengalikan jumlah skor indikator dengan bobot indikator sehingga hasilnya dapat dilihat seperti pada tabel dibawah ini:

Tabel 9. Jumlah Skor Tertimbang

\begin{tabular}{llll}
\hline Prespektif & $\begin{array}{l}\text { Jumlah skor } \\
\text { tertimbang }\end{array}$ & Bobot indikator & Skor \\
\hline Keuangan & 10 & 6,5 & 65 \\
Stakeholder & 8 & 8,3 & 66 \\
Bisnis internal & 12 & 6,25 & 75 \\
Learning and growth & 10 & 8 & 80 \\
\hline Jumlah Skor Tertimbang & & 286 \\
\hline
\end{tabular}

Sumber: Data Diolah Peneliti

Selanjutnya, jumlah skor tertimbang tersebut digunakan untuk menghitung nilai akhir total score. Dan untuk menghitung nilai akhir total atau total score digunakan rumus = (jumlah skor tertimbang / jumlah skor tertimbang maksimum) $\mathrm{x} 100 \%$. Sehingga diperoleh hasil total score $=(286 / 351) \times 100 \%=81,4 \%$. Kemudian dilihat dari kriteria standar: 


\begin{tabular}{lll}
\hline \hline \multicolumn{3}{c}{ Tabel 10. Kriteria Standar Penilaian } \\
\hline Kondisi & Kategori & Total score \\
\hline SANGAT SEHAT & AAA & $\geq 95$ \\
AA & $80<\mathrm{TS}<95$ \\
KURANG SEHAT & A & $65<\mathrm{TS}<80$ \\
& BBB & $50<\mathrm{TS}<65$ \\
& BB & $40<\mathrm{TS}<50$ \\
TIDAK SEHAT & B & $30<\mathrm{TS}<40$ \\
& CCC & $20<\mathrm{TS}<30$ \\
& CC & $10<\mathrm{TS}<20$ \\
& C & TS $<10$ \\
\hline
\end{tabular}

Sumber: Rangkuti Freddy (2011: 147)

Maka dapat ditarik kesimpulan hasil pengukuran kinerja dengan menggunakan Balanced Scorecard pada Pabrik Gula Lestari Kertosono diperoleh nilai dengan total score $81,4 \%$ sehingga masuk dalam kondisi Sangat Sehat kategori AA.

\section{PENUTUP}

\section{Kesimpulan}

Hasil pengukuran kinerja yang dihasilkan peneliti di Pabrik Gula Lestari Kertosono dengan menggunakan balance scorecard, dapat disimpulkan bahwa:

1. Hasil dari keseluruhan pengukuran kinerja dengan menggunakan balanced scorecard pada Pabrik Gula Lestari Kertosono pada tahun 2010 sampai 2012 berada dalam kondisi Sangat Sehat kategori AA dengan total score 81,4\%

2. Hasil pengukuran prespektif keuangan, yaitu Return on Investment, Total Asset Turn Over, Fixed Asset Turn Over, Gross Profit Margin Pabrik Gula Lestari Kertosono tahun 2010 sampai 2012 menunjukkan hasil yang cukup baik, walaupun masih terdapat nilai yang belum maksimal.

3. Hasil pengukuran prespektif stakeholder tahun 2010 sampai 2012 menunjukkan hasil bahwa rata-rata akuisisi stakeholder 5,8\%, tingkat retensi stakeholder 87,9\% dan profitabilitasnya $19,58 \%$, sehingga untuk prespektif ini menunjukkan tingkat kinerja yang baik.

4. Hasil pengukuran prespektif Proses Bisnis Internal, yaitu tercapainya target produksi pada tiap-tiap tahun dari tahun 2010 sampai 2012, terpenuhinya kapasitas giling harian tebu, berkurangnya jam berhenti giling, dan target rendemen pabrik terpenuhi. Jadi, dapat disimpulkan bahwa kinerja prespektif ini adalah baik.

5. Hasil pengukuran prespektif pembelajaran dan pertumbuhan juga menunjukkan hasil yang baik, dengan melihat rata-rata tingkat retensi karyawan yang menunjukan $0 \%$, tingkat produktivitas karyawan Rp. 24.440.524,15 dan tingkat kepuasan karyawan $69,33 \%$.

\section{Saran}

Berdasarkan hasil analisis dan kesimpulan yang diperoleh, saran-saran yang diajukan bagi penelitian-penelitian selanjutnya adalah: Diharapkan memperhatikan nilai pada 
prespektif keuangan mengingat prosentase yang dihasilkan masih dibawah standar. Pada prespektif stakeholder, perusahaan perlu meningkatkan tingkat pemerolehan stakeholder baru mengingat prosentase pada sektor ini mengalami penurunan pada tiap tahunnya, mungkin dengan melakukan promosi atau kebijakan lain yang dapat menarik minat petani

\section{DAFTAR PUSTAKA}

Arikunto Suharsimi. 2010. Prosedur Penelitian (Suatu Pendekatan Praktik). Jakarta: Rineka Cipta.

Edwin dan Se Tin. 2011. Evaluasi Penerapan Balance Scorecard terhadap Efisiensi Kinerja Karyawan Di Divisi Penjualan PT AUTO 2000. Jurnal Akurat Ilmiah Nomor 06.

Efendi Rizal. 2012. Pengukuran Kinerja Sektor Publik Dengan Menggunakan Balance Scorecard (Studi kasus Kanwil DJP Sumsel dan Kep. Babel). Jurnal Ilmiah STIE MDP Vol. 1 No. 2.

Erlinda dan Setio. 2006. Perancangan Balance Scorecard sebagai Alat Pengukur Kinerja Perusahaan (Studi kasus: PT. MCA). Seminar on application and research in industrial technology, SMART 2006.

Hanuma Soraya. 2010. Analisis Balance Scorecard sebagai Alat Pengukur Kinerja Perusahaan (Studi Kasus pada PT Astra Honda Motor). Penelitian Dipublikasikan. Semarang: Fakultas Ekonomi Universitas Diponegoro Semarang.

Irviana dan Nurkholis. Analisis Pengukuran Kinerja Perusahaan Dengan Pendekatan Balance Scorecard (Studi Kasus pada PT Rajawali I unit PG Krebet Baru). Jurnal publikasi. Diakses tanggal 23 April 2013.

Krismiaji dan Anni. 2011. Akuntansi Manajemen. Yogyakarta: Unit Penerbit dan Percetakan Sekolah Tinggi Ilmu Manajemen YKPN.

Listyani ika. 2006. Analisis Dan Perancangan Alat Pengukur Kinerja Dengan Metode Balance Scorecard Pada Sub Direktorat Property And Facilities Management PT Indosat, Tbk. Penelitian dipublikasikan. Bogor. Institute Pertanian Bogor.

Mardiasmo. 2009. Akuntansi Sektor Publik. Yogyakarta: Penerbit Andi.

Mathius dan Erna. 2011. Penerapan Balance Scorecard Sebagai Alat Pengukuran Kinerja Yang Memadai (Studi Kasus Pada Perusahaan Bio Tech Sarana di Bandung). Jurnal Ilmiah Akuntansi Nomor 05.

Moeheriono. 2010. Pengukuran Kinerja Berbasis Kompetensi. Bogor. Ghalia Indonesia.

Mulyadi. 2009. Sistem Terpadu Pengelolaan Kinerja Personel berbasis BALANCE SCORECARD. Yogyakarta: UPP STIM YKPN.

Rangkuti Freddy. 2011. SWOT Balance Scorecard (Teknik Menyusun Strategi Korporat Yang Efektif Plus Cara Mengelola Kinerja Dan Resiko). Jakarta: Gramedia Pustaka Utama. 
Sinaga Pariaman. 2004. Balanced Scorecard Sebagai Pengukuran Kinerja Koperasi dan UKM. Apa Mungkin?. Infokop Nomor 25 Tahun XX.

Sugiyono. 2010. Metode Penelitian Pendidikan Kuantitatif Kualitatif dan R\&D. Bandung: Alfabeta.

Sugiyono. 2012. Metode Penelitian Kuantitatif Kualitatif dan R\&D. Bandung: Alfabeta.

Susanto Irwan, dkk. 2004. Balance Scorecard Sebagai Alat Pengukuran Kinerja Manajemen (Studi Kasus Pada PT Sari Husada). Jurnal pendidikan Akuntansi Indonesia Vol. III No. 1 hal 40-50.

Wahyuni Sri. 2011. Analisis Balance Scorecard Sebagai Alat Pengukuran Kinerja pada PT. SEMEN BOSOWA MAROS. Penelitian Dipublikasikan. Makasar: Fakultas Ekonomi Universitas Hassanudin Makasar.

Widodo Iman. 2011. Analisis Kinerja Perusahaan Dengan Menggunakan Pendekatan Balance Scorecard (Studi Kasus pada Perusahaan Mebel PT. Jansen Indonesia). Penelitian dipublikasikan. Semarang. Fakultas Ekonomi Universitas Diponegoro Semarang.

Yuwono Sony dkk. 2002. Petunjuk Praktis Penyusunan Balance Scorecard (Menuju Organisasi Yang Berfokus Pada Strategi). Jakarta: Gramedia Pustaka Utama.

Zudia Meirdania. 2010. Analisis Penilaian Kinerja Organisasi Dengan Menggunakan Konsep Balance Scorecard pada PT Bank Jateng Semarang. Penelitian dipulikasikan. Semarang. Fakultas Ekonomi Universitas Diponegoro Semarang. 